\title{
VALORACIÓN DE LA INFLUENCIA SOCIOECONOMICA Y TERRITORIAL DE LOS ESPACIOS NATURALES PRO- TEGIDOS. EL CAÑÓN DEL RÍO LOBOS
}

\author{
Jesús María BACHILLER MARTINEZ \\ Dpto. de Geografía. Universidad de Valladolid
}

Recibido: 10/02/2014

Aceptado: 04/08/2014

RESUMEN: Los espacios naturales protegidos ejercen un papel fundamental en la ordenación de las zonas rurales. El entramado legislativo que hay detrás de ellos delimita los parámetros de su planificación territorial y define su funcionalidad, no solo orientada a la conservación sino a su aprovechamiento como recurso económico. La amalgama de factores que interactúan en estos espacios permite un análisis desde múltiples puntos de vista. Este artículo trata de mostrar la influencia de uno de los espacios protegidos más antiguos de Castilla y León, el Cañón del Rio Lobos. En base a la experiencia acumulada a lo largo de sus más de 25 años de vigencia, se efectúa una reflexión sobre cuál ha sido su significado para los municipios incluidos dentro del Parque, realizada a través de la opinión de sus propios habitantes y de la evolución de distintos indicadores.

PALABRAS CLAVE: Espacios naturales protegidos, Cañón del Río Lobos, indicadores socioeconómicos, opinión de los habitantes.

\section{THE TERRITORIAL INFLUENCE OF THE PROTECTION OF NATURAL SPACES. LO-} BOS RIVER CANYON

ABSTRACT: Protected natural areas exercise a fundamental role in the management of rural areas. The legislative framework behind them delimits the parameters of its territorial planning and defines its functionality, not only aimed at their preservation, but also at its use as an economic resource. The mixture of factors that interact in these spaces allows an analysis from multiple perspectives/ points of view. This article tries to show the geographical meaning of one of the oldest protected areas of Castilla y León, Rio Lobos Canyon. Based on experience accumulated over more than 25 years of operation, a reflection is made on what has been the significance of that legislation for the municipalities included within the park, derived from the opinion of its own inhabitants and the evolution of different indicators.

KEY WORDS: Protected natural areas, Lobos river canyon, socioeconomic indicators, opinion of the inhabitants. 


\section{OBJETIVOS}

Los espacios naturales protegidos constituyen un magnífico ejemplo de ordenación y gestión de unos territorios cada vez más extensos, que, como depositarios de unos valores ambientales, han justificado una regulación administrativa detallada, en la que se incluyen aspectos tan relevantes como la ordenación de los recursos naturales, los planes de uso y gestión, o la política de concesión de ayudas a los municipios afectados. Todo ello ha generado un complejo entramado de actuaciones públicas, cuya potencial influencia en los territorios implicados está adquiriendo un interés creciente.

El objetivo de este artículo es hacer una valoración del impacto que ha tenido la declaración del parque natural del cañón del río Lobos, el segundo más antiguo de Castilla y León, realizada a través de la opinión de sus propios habitantes, la de un grupo de expertos y el estudio comparativo de diferentes indicadores socioeconómicos. La primera permitirá conocer la percepción que tiene la población local acerca de la influencia que ha ejercido la creación del Parque; la segunda proporcionará una valoración más técnica del significado económico y territorial que ha desempeñado este espacio y las medidas puestas en marcha a lo largo de su ya prolongada vigencia, y el tercero permitirá establecer una aproximación, con datos reales, de cuál ha sido el verdadero impacto de la protección.

El cañón del río Lobos, situado entre las provincias de Soria y Burgos, fue declarado parque natural en 1985, a través del Decreto 115/1985. Se han cumplido, por tanto, más de 25 años desde su aprobación, que es un periodo de convivencia lo suficientemente amplio como para que los vecinos tengan una idea formada de cuál ha sido su impacto socioeconómico y ambiental, y lo suficientemente dilatado como para poder observar con perspectiva la evolución socioeconómica de los municipios afectados, y extraer algunas conclusiones mínimamente fundamentadas. El Cañón del Río Lobos ofrece también diversos alicientes por el hecho de ser un parque que se extiende a través de dos provincias -las de Burgos y Soria- y afectar a un número elevado de municipios -siete en total- con características y problemáticas muy distintas. Asimismo, se trata de un Parque en el que se manifiesta muy bien el actual debate entre conservación y uso recreativo, ya que presenta uno de los sistemas más avanzados de protección de Castilla y León. No solo ha obtenido la Q de calidad turística, sino que es uno de los pocos que ha instaurado un sistema de seguimiento, basado en la observación de 44 indicadores. 
Figura 1: Localización del parque natural del Cañón del río Lobos

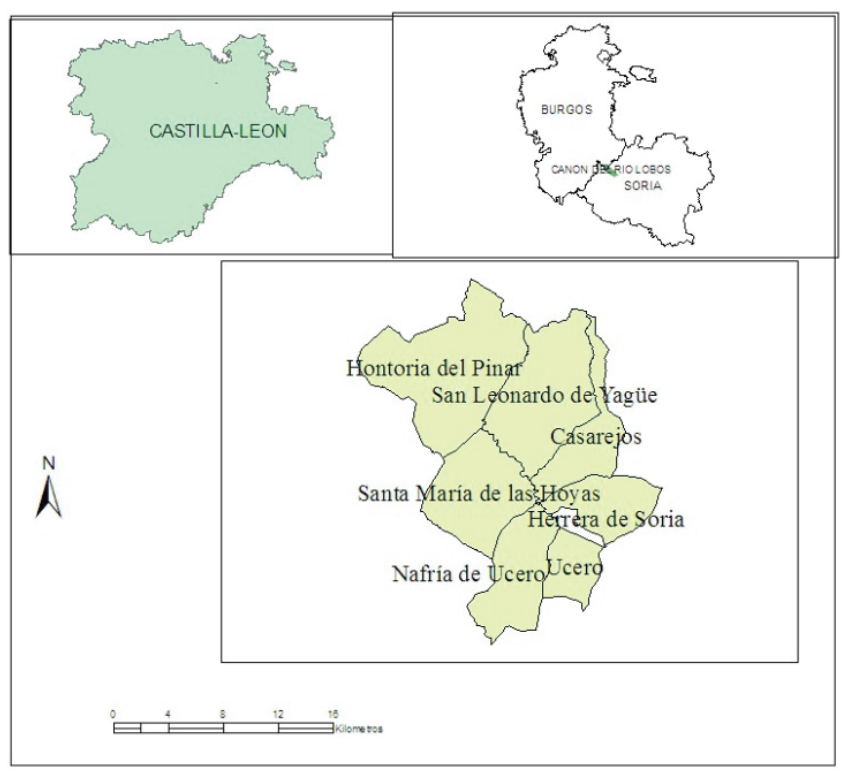

\section{METODOLOGÍA}

Para cumplir estos objetivos, se ha recabado la opinión de la población local a través de una encuesta, realizada mediante entrevistas personales, a la que se ha añadido la valoración de un grupo de expertos mediante un cuestionario de diez preguntas, en las que se recogían diversos aspectos de la gestión y la proyección del Parque en los distintos ámbitos socioeconómicos y territoriales. Para valorar los supuestos beneficios socioeconómicos de la conversión de un territorio en un espacio natural protegido, se ha estudiado la evolución de distintos indicadores demográficos y económicos de los municipios afectados.

La respuesta a esta última cuestión no resulta fácil, pues solo podría darse teniendo en cuenta los distintos contextos, temporal y espacial, en que se enmarca el espacio implicado. Habría que calcular cómo hubiera sido la evolución de esos municipios sin la catalogación jurídica de espacio protegido. Una primera valoración podría hacerse estableciendo una comparación con la trayectoria de otros territorios vecinos o con condiciones ambientales equivalentes. Pero también habría que estimar cuál habría sido el grado de evolución si se hubiera optado por otras oportunidades de desarrollo, no compatibles con la conservación, bien en el momento de creación del parque o considerando las nuevas oportunidades que 
hayan podido surgir a lo largo de su vida como espacio protegido. Sea cual sea el signo de la evolución, habría que valorar también en qué medida se debe a la declaración del parque o a otros factores ajenos a él. Para efectuar una aproximación lo más objetiva posible, se ha seguido un método comparativo, confrontando su evolución con la del resto de municipios rurales de la provincia de Soria o, en algunos casos, con la de los municipios colindantes.

Con todos los datos reunidos, se hace una valoración final, para la que se tiene en cuenta dos de los elementos que más influencia ejercen en el devenir de estos espacios y en la creación de una corriente de opinión sobre esta política de cualificación del territorio: En primer lugar, su atractivo turístico y la ordenación de los distintos sectores, y, en segundo lugar, la política de ayudas destinadas a este parque natural, su distribución entre los distintos términos y su importancia dentro de los presupuestos globales de los municipios implicados.

\section{LA PERCEPCIÓN DE LA POBLACIÓN LOCAL}

La opinión de la población local se ha recabado de forma directa a través de una encuesta estructurada, con temas previamente establecidos, en la que se combinan preguntas cerradas con preguntas abiertas, cumplimentadas mediante entrevistas individuales a personas seleccionadas teniendo en cuenta dos variables: los sectores económicos del área de influencia socioeconómica del Parque y la distribución de los mismos en los distintos municipios. Dada la antigüedad de este espacio protegido, se han elegido personas adultas, con una edad superior a los 30 años, y con una residencia permanente en los pueblos, a fin de que pudieran acreditar una cierta experiencia en su relación con el Parque. Al tratarse de un sondeo cuyo objetivo fundamental es valorar la influencia socioeconómica del Parque, con los distintos aspectos de organización, gestión, etc. implícitos en ella, parecía más adecuado plantear un muestreo por cuotas teniendo en cuenta esas dos variables. Con ellas se evitaba también la distorsión que podía derivarse de la presencia de una importante industria en la localidad de San Leonardo de Yagüe, que absorbe a más del 58\% del empleo de la comarca.

De esta forma, se han realizado un total de 50 entrevistas a pequeños empresarios, profesionales y autónomos, y responsables de servicios públicos y privados, siguiendo un muestreo por cuotas, ajustado a las condiciones previstas. Las encuestas se han desarrollado mediante entrevistas personales en un laborioso trabajo de campo que se prolongó desde octubre de 2009 a septiembre de 2010. Los porcentajes de representación en la muestra de las distintas cuotas se detallan en el cuadro 1. 
Cuadro 1: Representación en la muestra de las dos cuotas seleccionadas

\begin{tabular}{|l|r|r|r|r|}
\hline CATEGORÍAS & Muestra & \% en muestra & Universo & \% en universo \\
\hline Sectores económicos: & & & & \\
Sector agrario & 7 & 14,0 & 38 & 11,1 \\
Industria & 9 & 18,0 & 49 & 14,4 \\
Construcción & 7 & 14,0 & 64 & 18,8 \\
Servicios & 27 & 54,0 & 190 & 55,7 \\
\hline Municipios: & 4 & & & \\
Casarejos & 2 & 8,0 & 16 & 4,7 \\
Herrera de Soria & 2 & 4,0 & 3 & 0,9 \\
Nafría de Ucero & 18 & 36,0 & 6 & 1,8 \\
San Leonardo de Yagüe & 7 & 14,0 & 31 & 60,4 \\
Santa María de las Hoyas & 7 & 14,0 & 12 & 9,1 \\
Ucero & 10 & 20,0 & 67 & 3,5 \\
Hontoria del Pinar & 50 & 14,66 & 341 & 19,6 \\
\hline TOTAL & & & & 100 \\
\hline
\end{tabular}

FuENTE: Elaboración propia a partir de los datos de licencias de Camerdata y datos de la Tesorería de la S.S.

La proporcionalidad de los sectores económicos se ha respetado en las distintas ramas de actividad del sector servicios, de forma que en la de turismo se han realizado 14 entrevistas $(28,0 \%)$, en la rama de comercio 6 entrevistas $(12,0 \%)$ y 7 entrevistas en el apartado de otros servicios (14,0\%). Un $34,0 \%$ son adultos-jóvenes, con edades comprendidas entre 30 y 44 años, un $60,0 \%$ adultos y un $6,0 \%$ personas mayores de 65 años. La mayor parte de los encuestados son varones - $82 \%$ - y más de la mitad tienen estudios medios o de formación profesional, un $34 \%$ estudios primarios y un $14 \%$ titulación universitaria. La información se ha tabulado a través del programa Office Access.

\section{III.1 La contribución del Parque al desarrollo de los municipios incluidos en su zona de influencia socioeconómica}

Pese a lo que inicialmente pueda pensarse, existe una valoración positiva de la presencia del Parque, que desmitifica un poco la idea de rechazo que se atribuye a las poblaciones locales afectadas. Hay un sentimiento mayoritario de mayor identificación con el Cañón y una percepción bastante generalizada de que la protección de este espacio ha favorecido el desarrollo de los municipios. Así 
lo afirma un $86 \%$ de los encuestados. Además, un $65 \%$ de estos opina que ha beneficiado mucho o bastante, por un 35\% que considera que solo ha beneficiado algo o muy poco. Solo 4 entrevistados, el $8 \%$ del total, piensa que ha perjudicado y un $4 \%$ que ni ha favorecido ni perjudicado.

La valoración más positiva procede, como cabría esperar, del sector turístico, y también del de otros servicios, con un $71 \%$, seguido del comercio y la industria, con el 66,6\% cada uno. Cabe significar que hay una inmensa mayoría de encuestados procedentes del sector agrario que reconocen también el efecto beneficioso del Parque, pese a ser hipotéticamente el sector económico más perjudicado. Ninguno de los encuestados expresa que el Parque haya traído efectos negativos para la comarca, lo cual manifiesta un reconocimiento expreso de sus potencialidades, especialmente significativo al provenir de una posición de desventaja en relación con otros sectores. Los mayores descontentos provienen del municipio burgalés de Hontoria del Pinar, sobre todo del sector de la construcción, debido a la normativa que prohíbe la instalación de parques eólicos. Como en tantas ocasiones, los aerogeneradores son percibidos como un factor de desarrollo, por encima de cualquier valoración del paisaje y del patrimonio natural.

Cuadro 2: Influencia socioeconómica del parque natural Cañón del río Lobos en \%

\begin{tabular}{|l|r|r|r|r|r|r|r|r|}
\hline ACTIVIDADES & \multicolumn{1}{|c|}{1} & \multicolumn{1}{|c|}{2} & \multicolumn{1}{|c|}{3} & \multicolumn{1}{c|}{4} & \multicolumn{1}{c}{5} & 6 & \multicolumn{1}{c|}{7} & 8 \\
\hline Agricultura & 4,0 & 0 & 0 & 68,0 & 18,0 & 2,0 & 2,0 & 6,0 \\
Ganadería & 6,0 & 2,0 & 0 & 54,0 & 30,0 & 2,0 & 2,0 & 4,0 \\
Explotación forestal & 8,0 & 0 & 0 & 60,0 & 20,0 & 6,0 & 0 & 6,0 \\
Caza & 4,0 & 2,0 & 0 & 60,0 & 20,0 & 2,0 & 4,0 & 8,0 \\
Industria & 16,0 & 4,0 & 0 & 70,0 & 4,0 & 0 & 0 & 6,0 \\
Construcción & 42,0 & 8,0 & 2.0 & 40,0 & 6,0 & 0 & 0 & 2,0 \\
Alojamientos turísticos & 24,0 & 40,0 & 36,0 & 0 & 0 & 0 & 0 & 0 \\
Restauración & 26,0 & 38,0 & 32,0 & 6,0 & 0 & 0 & 0 & 0 \\
Comercio & 50,0 & 20,0 & 10,0 & 16,0 & 2,0 & 0 & 0 & 2,0 \\
Vías de comunicación & 36,0 & 18,0 & 6,0 & 30,0 & 6,0 & 0 & 4,0 & 2,0 \\
Abast./depur. de aguas & 34,0 & 14,0 & 12,0 & 28,0 & 8,0 & 0 & 0 & 4,0 \\
Recogida de basuras & 48,0 & 8,0 & 8,0 & 22,0 & 6,0 & 2,0 & 0 & 6,0 \\
Seguridad & 8,0 & 0 & 2,0 & 82,0 & 6,0 & 0 & 0 & 2,0 \\
\hline
\end{tabular}

1: Algo beneficiado; 2: Bastante beneficiado; 3 : Muy beneficiado; 4: Ni beneficiado, ni perjudicado; 5: Algo perjudicado; 6: Bastante perjudicado; 7: Muy perjudicado; 8: NS/NC 
En la pregunta $\mathrm{n}^{0} 3$ se pretendía obtener de los encuestados una valoración más específica de la influencia socioeconómica sobre los distintos sectores. Los resultados ofrecen datos sumamente interesantes, que se muestran en la tabla $\mathrm{n}^{\mathrm{o}} 2$. Un primer análisis pone de relieve el gran desequilibrio existente entre las columnas 2 y 3 (bastante y muy beneficiado) y las columnas 6 y 7 (bastante y muy perjudicado) con un saldo claramente favorable a las primeras, lo cual revela que, en la concepción de los vecinos, no existe ninguna actividad visiblemente perjudicada, pero sí algunas manifiestamente beneficiadas. Las actividades relacionadas con el sector primario son las que soportan, a juicio de la población, un mayor impacto por la declaración, pero no de una forma muy negativa. Son muy pocos los que piensan que estén bastante o muy perjudicadas y, además, ninguno procede del propio sector. Los que más reconocen este impacto negativo son los del sector servicios. Llama la atención también que se considere a la ganadería una actividad más perjudicada que la agricultura.

Por el contrario, existe una opinión casi generalizada de que el Parque Natural ha beneficiado especialmente al sector turístico. Un $76 \%$ señala que ha beneficiado bastante o mucho a los alojamientos turísticos y un $70 \%$ a los servicios de restauración. Dentro de este grupo también habría que incluir al comercio, con un $30 \%$ de los encuestados. Todos los sectores sin exclusión ven al turismo como el principal beneficiario de la declaración del Parque; entre ellos, el 100\% del comercio, el $85,7 \%$ de la construcción o el 71,4\% de los encuestados del sector primario. Paradógicamente, esta percepción es menor en el propio sector, ya que solo un $64,2 \%$ se consideran bastante o muy beneficiado.

El sector industrial aparece como el más desvinculado de la presencia del Parque, ya que más de dos de cada tres encuestados no advierten una incidencia directa, ni favorable ni desfavorable. Solo un 16\% le concede algún beneficio, de los cuales un $37.5 \%$ pertenecen al propio sector, que ven en la llegada de turistas una oportunidad de darse a conocer. Otros sectores presentan una mayor dispersión, como sucede con la construcción, cuyas respuestas se dividen prácticamente entre los que no ven ninguna influencia (40\%) y los que ven algún beneficio (42\%) o bastante beneficio (8\%). La razón principal hay que buscarla en la capacidad de arrastre que tiene la dinámica turística y residencial.

La influencia del Parque sobre las distintas infraestructuras y servicios de los municipios reciben, por lo general, valoraciones positivas, que tienen mucha relación con el impacto de las ayudas percibidas y de la propia política del gobierno regional en favor de estos espacios. Las vías de comunicación, el abastecimiento/depuración de aguas y la limpieza son las que, a juicio de los encuestados, se han beneficiado de forma más significativa. Las únicas opiniones negativas, 
aunque poco relevantes, ponen de relieve cierto descontento con el funcionamiento de varias depuradoras instaladas, sobre todo la de su cabecera, o, en el caso de las carreteras, con la falta de comunicación entre el sector norte y sur del Parque. El hecho de encontrarse junto a la entrada principal, en uno de los espacios de mayor valor paisajístico y ambiental, ha impedido una intervención más profunda por los impactos que pueda ocasionar. La consecuencia directa es que los vehículos pesados (camiones y autocares) encuentran dificultades para transitar. Ello ha generado descontento y el reclamo de soluciones, que podrían venir de la apertura de un nuevo tramo por un lugar más lejano y con menor impacto.

Una de las preguntas que puede encajar en este apartado es la que pedía opinión sobre qué municipio había resultado más favorecido por la declaración del Parque. Y la respuesta evidencia una visión bastante localista de la realidad, ya que tan solo cuatro los entrevistados, reconoce que haya sido su propio pueblo. De los siete municipios que integran el área de influencia socioeconómica, el que se señala como más favorecido es Ucero, que es uno de los caseríos más pequeños y con menor superficie de Parque, pero que goza de una ventaja comparativa al estar situado en la entrada principal del Cañón, donde se ha instalado también la casa del parque. Lo proclama un $44 \%$ de los encuestados. El segundo es San Leonardo de Yagüe, con un 26\%. Solo hay un $4 \%$ que reconoce explícitamente que el Parque ha supuesto un beneficio para todos los municipios. También aparece como uno de los más beneficiados, a pesar de no situarse dentro del espacio protegido, el municipio de El Burgo de Osma, con un 24\% de los encuestados. La presencia de esta localidad en la concepción de los habitantes del Cañón se debe a que, no solo es uno de los centros turísticos más importantes de la provincia de Soria, sino que se beneficia además de su posición estratégica en la principal ruta de entrada al Parque, la que proviene de Madrid, que es el principal centro emisor. Se critica especialmente la política de infraestructuras, al no habilitar una salida directa hacia el parque natural desde la variante desdoblada de esta localidad, ni una señalización adecuada. Un hecho que concita un cierto sentimiento de discriminación.

\section{III.2 Una valoración positiva de la gestión del parque}

La gestión de un espacio natural protegido tiene una importancia clave para conseguir un nivel de complicidad suficiente en la población local. Dicha gestión demanda de las administraciones implicadas un trabajo meticuloso en una multiplicidad de campos, que interactúan dentro del territorio afectado. Desde la calidad de los servicios prestados, la gestión de los accesos, el equilibrio en la administración de las ayudas y planificación de las inversiones, la organización 
y distribución de las infraestructuras y equipamientos, hasta el conocimiento y difusión del espacio natural. En la medida que se logre una perfecta armonía entre la administración y los administrados será más fácil conseguir una mejor convivencia con la nueva ordenación de los recursos y, en última instancia, el cumplimiento de los objetivos de protección previstos. Por ello, el segundo grupo de preguntas iba dirigido a valorar la gestión del Parque. Los resultados son en general positivos, ya que hay una opinión mayoritaria que valora la gestión como buena (un $42 \%$ ) o muy buena (un 10\%). Sin embargo, no es despreciable el número de encuestados que la ven indiferente -uno de cada cuatro- o la consideran mala -un $14 \%$ -

Las respuestas positivas respecto a la gestión proceden en un $73 \%$ de los servicios, aunque se detecta un cierto descontento en la rama turística, ya que hay un $42,8 \%$ de encuestados que la califican con indiferencia o como mala. Las opiniones más negativas o indiferentes proceden sobre todo de la actividad agraria y de la construcción, con un $57 \%$ de sus respectivos sectores. Resulta significativa la procedencia geográfica de estas valoraciones. Las opiniones más negativas se alzan desde los municipios de Ucero, que es uno de los más beneficiados, y Hontoria del Pinar, que se siente discriminado con una gestión que se decide básicamente en Soria. En el primero hay un $85,7 \%$ de encuestados que califica la gestión como mala o indiferente, por un 50\% en el segundo.

A pesar de la buena valoración, hay un $60 \%$ de los entrevistados que señalan algún tipo de desacuerdo con la gestión, siendo proporcionalmente más numerosas las que proceden de los municipios de Ucero, Santa María de las Hoyas (el segundo municipio que más superficie aporta) y Hontoria del Pinar. Las discrepancias sacan a la luz temas de muy variada naturaleza. Unos ponen el foco en las limitaciones impuestas por la declaración (circulación de vehículos, prohibición de aerogeneradores...). Otros muestran descontentos con el reparto de las ayudas, con la política de información y promoción, con la ampliación contemplada en el PORN, o con otros aspectos más puntuales como el olvido hacia el sector burgalés del Parque (que aporta la mayor superficie municipal) o el abandono que sufren algunos caminos.

Resultan también llamativas las respuestas a la hora de valorar las ventajas y desventajas que había contraído la declaración del Parque para la población local. Dos de cada tres entrevistados piensa que la principal y casi única ventaja del Parque es el turismo y la actividad comercial vinculada a él. Son una reducida minoría los que valoran otros aspectos, como la mejora que ha supuesto para los pueblos, para sus infraestructuras, o la oportunidad de darse a conocer. Llama la atención que ninguno de los entrevistados haya apreciado las posibles mejoras 
para la conservación del espacio natural, que redundaría positivamente en su calidad de vida, además de garantizar el mantenimiento del uso público.

Entre las desventajas comienza a aparecer una cierta preocupación por la degradación del Parque, debido a la presencia masiva de turistas (10\% del total). Cuando se habla de desventajas, hay un $30 \%$ de los entrevistados que se acuerdan principalmente de las limitaciones que se imponen, y un 38\% que no aprecian ninguna desventaja. Entre los primeros son mayoría los entrevistados que trabajan en el sector primario y en la construcción, mientras que entre los segundos son una mayoría los que representan al sector servicios y a la industria. Por municipios, los que más se quejan son los que han tenido una vinculación más estrecha con el espacio natural, Ucero por su proximidad y Herrera de Soria, que tiene un monte de socios privado dentro del Parque. En ambos casos, representa un 50\% de los encuestados.

\section{III.3 Influencia del Parque en la conservación del espacio}

El tercer bloque de preguntas pretendía que la población se postulara acerca de la influencia del Parque en la conservación de este espacio natural, y el nivel de respuesta e integración que ha encontrado entre la población local. Las respuestas a la primera pregunta no dejan lugar a duda del efecto beneficioso, ya que un $82 \%$ de los entrevistados así lo entiende. Las valoraciones se pueden calificar incluso de muy positivas si tenemos en cuenta que más de la mitad piensan que el cañón está bastante o mucho mejor conservado. Solo hay un $10 \%$ que declara estar peor conservado, debido sobre todo a los efectos que provoca el uso masivo del espacio público y el descenso de la carga ganadera.

El elemento que mejor representa la mejora de la conservación es la limpieza, resaltado por un $62 \%$ de los entrevistados, seguida de lejos por la fauna, la flora y el paisaje. Quizá lo más relevante es que hay un cierto porcentaje de personas que subrayan el hecho de que la declaración del Parque ha infundido en la población local un mayor respeto hacia los valores que atesora. En realidad, más del 70\% de los entrevistados reconoce tener mayor conciencia y mejor conocimiento de los valores de este paraje y la necesidad de conservarlo.

El bloque se cierra con dos preguntas que buscaban conocer el nivel de compromiso personal con el espacio natural. La primera, si habían cambiado sus usos o hábitos respecto a su relación con el Cañón y, la segunda, si se sentía más identificado con él que antes. Las respuestas recibidas no tienen en este caso una correlación exacta con las anteriores, quizá porque en el fondo nadie tiene conciencia de que se estuvieran cometiendo errores en la relación con el territorio del 
Parque, antes de su declaración. Un 54\% de los entrevistados dice que sus hábitos han cambiado muy poco, un $28 \%$ que han cambiado algo y solo un $16 \%$ que han cambiado bastante. Respecto a si se sienten más identificados, hay un $60 \%$ que responden de forma positiva, por un $38 \%$, que se sienten igual de identificados que antes. Hay un $34 \%$ que declara sentirse bastante o mucho más identificado, lo cual prueba de alguna manera que existe un cierto orgullo de pertenencia y que se ha conseguido una cierta comunión entre el Parque y la población que vive en él. La conclusión que podemos extraer es que los encuestados valoran de forma muy positiva el impacto del Parque sobre la población local, pero son algo más remisos a la hora de enjuiciar el efecto sobre las conductas personales.

\section{LA INFLUENCIA DE LA DECLARACION DEL PARQUE NATU- RAL SEGÚN LA OPINIÓN DE LOS EXPERTOS}

Aparte de la población local, que mantiene una relación diaria con el Parque, hay numerosos profesionales y agentes sociales que, por diferentes motivos, son conocedores de la realidad que envuelve a los espacios protegidos y guardan una opinión formada sobre la influencia que hayan podido ejercer, que resulta interesante recoger. Para ello, se ha pasado un cuestionario de diez preguntas a cinco agentes sociales, entre los que figuran representantes de la administración, miembros de una conocida asociación ecologista y trabajadores del Parque. Las respuestas recogen ideas interesantes, algunas de las cuales están en sintonía con las opiniones emitidas por la población local.

La impresión general es que ha habido una influencia socioeconómica positiva, si bien dentro no se han aprovechado todas sus potencialidades y su capacidad de influencia desborda el perímetro del Parque. Existe una cierta coincidencia de que ha tenido pocos o ningún efecto negativo, aunque la excesiva focalización del turismo en unos espacios concretos, ha acabado por sobreexplotarlos. También existe una coincidencia en que el sector turístico es el más beneficiado, quizá con demasiado protagonismo para algunos. Son varios los que destacan que el hecho de ser un parque de referencia a nivel nacional, ha contribuido a consolidarle como un producto turístico de calidad, habiendo unanimidad en que los pueblos más grandes y con mayores capacidades, han sido los más beneficiados.

Otro de los aspectos positivos de la declaración del Parque es el ámbito de la conservación, que uno de los encuestados materializa en una mejora del conocimiento de los ecosistemas, en la consolidación de los sistemas de gestión del medio natural y en una mayor protección jurídica frente a proyectos más agresivos para el medio. Pero desde esta óptica, existe una división de opiniones 
entre los que señalan que se han cumplido los objetivos de declaración, e incluso aplauden el grado de integración entre conservación y aprovechamiento en los montes, y los que opinan que se ha abusado del uso público y eso ha significado un deterioro en algunos sectores. Exponen, por ejemplo, que algunas aves han dejado de anidar e insisten en que se han deteriorado algunos lugares con un uso turístico excesivo. Desde la perspectiva del desarrollo económico, una mayoría reconoce que no se han conseguido los objetivos, y ponen a la falta de iniciativa local como su principal causa.

Existe unanimidad en que las limitaciones impuestas han sido eficaces para la conservación del espacio. Se destaca en general que estas no han sido muy notables para la población local, excepto la restricción de accesos de vehículos y la eliminación progresiva de las choperas de producción en la parte baja del cañón. Los más críticos declaran que las limitaciones han ido detrás de los acontecimientos, como ha sucedido con la restricción de acceso a vehículos.

Hay, por último, un reconocimiento general de que la intervención ha sido en muchos aspectos pionera, destacando la falta de intervenciones excesivamente agresivas. Solo hay una voz discordante que apunta que en el lado de las ayudas ha habido una política destinada más a contentar a los pueblos, con nuevas inversiones, que a mejorar el espacio natural. La mayoría de los expertos reconocen que la población local está ahora más orgullosa del Parque y sus hábitos son más respetuosos en el uso y disfrute del espacio natural, hasta el punto de que la población siente el Parque como algo propio, sobre todo entre los jóvenes. Hay una respuesta interesante que alude al hecho de que como las limitaciones en el espacio han afectado más al uso social que al manejo del medio, la población local no ha tenido grandes problemas de adaptación.

\section{SIGNIFICADO DEL PARQUE EN SU ZONA DE INFLUENCIA SO- CIOECONÓMICA, MEDIDA A TRAVÉS DE DISTINTOS INDICA- DORES}

Siguiendo la línea argumental marcada, una vez expuestas las opiniones expresadas por los vecinos y conocidas las valoraciones fundamentadas de varios expertos, nos proponemos ahora hacer un análisis más detallado del impacto que el parque natural del Cañón del Río Lobos ha ejercido sobre su área de influencia cercana, en base al seguimiento de distintos indicadores y la comparación de los mismos con la evolución experimentada en otros espacios, tomando como base la provincia de Soria. 


\section{V.1 Análisis y valoración de los indicadores demográficos}

Durante los años que median entre 1986 y 2011, la población del conjunto de municipios del área de influencia del Cañón del Río Lobos descendió en 532 habitantes, que representa un 13\% menos. Este descenso, en conjunto, es muy inferior al del resto de municipios rurales de la provincia, que en el mismo periodo obtuvo una caída del $26,1 \%$, lo cual puede demostrar, en primera instancia, el efecto positivo de la declaración del Parque. Sin embargo, su evolución demográfica está condicionada por la presencia de un núcleo con una cierta tradición industrial, San Leonardo de Yagüe, que distorsiona las estadísticas de población Si restamos el peso de este municipio, el descenso es superior al del resto de municipios rurales, por lo que no se puede decir claramente que haya habido una gran influencia del espacio protegido o, por lo menos, que esa influencia haya afectado a todos los municipios por igual. El Parque ha servido, más bien, para fortalecer la situación de otros municipios más dinámicos, situados fuera de la superficie protegida. El principal de ellos es El Burgo de Osma, a escasos 15 minutos de la entrada principal, que ha catalizado gran parte del movimiento turístico, contribuyendo a reforzar su sector servicios. No es de extrañar, por tanto, que los resultados de la encuesta señalaran a este municipio como uno de los más favorecido por la declaración del Parque.

La estructura demográfica vuelve a reflejar esta circunstancia. Los índices de envejecimiento y las tasas de dependencia son comparativamente mejores en el conjunto de municipios del Cañón, pero arrojan valores mucho más elevados a los de la media de los municipios rurales si quitamos el peso del núcleo principal. El descenso de la población joven y adulta-joven permite concluir que la declaración del Parque no ha sido un revulsivo para que a lo largo de todo este largo periodo de tiempo surgieran iniciativas que pudieran retener o atraer a la población joven. Pero el que existan municipios en los alrededores que resultan beneficiados no debe contemplarse como un hecho negativo, aunque en el fondo se pueda plantear una contradicción entre las poblaciones que sufren las limitaciones impuestas y las que en la práctica se ven más favorecidas. Puede ocurrir que la iniciativa surgida en esos núcleos de población venga a suplir la falta de demanda de inversión en los municipios integrados en el Parque, consiguiendo que una parte del presupuesto de viaje del turista se quede en la comarca. Puede ocurrir también que emprendedores de esos núcleos externos aprovechen las oportunidades que ofrece el Parque para movilizar sus recursos. 
Cuadro 3: Indicadores demográficos del Cañón del Río Lobos y resto de municipios rurales

\begin{tabular}{|c|c|c|c|}
\hline & $\begin{array}{l}\text { Cañón Río } \\
\text { Lobos }\end{array}$ & $\begin{array}{c}\text { Cañón sin el peso } \\
\text { de San Leonardo } \\
\text { de Yagüe }\end{array}$ & $\begin{array}{l}\text { Resto de } \\
\text { municipios } \\
\text { rurales }\end{array}$ \\
\hline \multirow[t]{2}{*}{ Habitantes: } & 4.083 & 1.952 & 40.586 \\
\hline & 3.551 & 1.266 & 29.986 \\
\hline Tasa de crecimiento anual & -0.05 & -1.35 & $-1,00$ \\
\hline \multirow{2}{*}{ Índice de envejecimiento } & 1,37 & 4,78 & 2,75 \\
\hline & 2,60 & 6,95 & 4,29 \\
\hline \multirow[t]{2}{*}{ Tasa de Dependencia } & 61,16 & 67,23 & 68,40 \\
\hline & 61,99 & 65,37 & 71,35 \\
\hline \multicolumn{4}{|l|}{$\begin{array}{l}\text { Variación estructura de la pobla- } \\
\text { ción 1991-2010 }\end{array}$} \\
\hline $0-14$ años & $-33,14$ & $-36,20$ & $-28,62$ \\
\hline $15-29$ & $-19,04$ & $-41,50$ & $-44,90$ \\
\hline $30-44$ & 13,8 & $-18,85$ & 30,63 \\
\hline 45-64 & 17,16 & $-22,99$ & 4,67 \\
\hline $65 \mathrm{y}+$ & 36,22 & $-7,20$ & $-0,15$ \\
\hline
\end{tabular}

FUENTE: INE. Elaboración propia

La evolución y distribución del número de empresas es un indicador que puede estimar el grado de influencia que ha ejercido un espacio natural. El número de empresas refleja una unánime concentración en el sector servicios, que revela el desarrollo de muchas pequeñas empresas, de muchos proyectos personales en sectores como el turismo o el comercio. El ejemplo del Cañón de Río Lobos resulta paradigmático, al corroborar el peso sobre el empleo que tenía la firma puertas Norma. Si la industria absorbía en 2009 el 62\% del empleo, en el caso de las empresas, a partir de las estadísticas de Caja España, el sector servicios integraba el $61 \%$ del total.

\section{V.2 Evolución de los indicadores económicos}

La evolución de los indicadores económicos puede reflejar el impacto que la declaración del Parque ha podido ejercer sobre los distintos sectores económicos, teniendo en cuenta que su influencia tiene efectos desiguales según el tipo de actividad. Una primera aproximación puede venir de la evolución del número de licencias que, en el conjunto de los municipios del sector soriano, creció 
entre 1986 y 2010 a un ritmo menor que el del resto de municipios rurales de la provincia, un $17,5 \%$ frente al $25,15 \%{ }^{1}$. Un análisis más pormenorizado desvela diferencias significativas entre unos sectores y otros.

Las actividades agrarias, tradicionalmente consideradas como las más perjudicadas por la declaración de un espacio natural, por ser las más vinculadas con el territorio, no se han visto, sin embargo, especialmente afectadas. Las opiniones emitidas por los trabajadores del sector han sido corroboradas por la realidad de las cifras, que arrojan una trayectoria menos negativa que la de otros municipios del entorno, no afectados por el Parque. Durante los años que median entre 1982 y 2010 los municipios del área de influencia del Cañón han reducido el censo de óvidos en un 43,8\%, que es una pérdida notablemente inferior a la de Espeja de San Marcelino y Fuentearmejil, que son dos municipios contiguos al Parque, cuyo descenso se eleva al 65,6\%. No parece pues, a la vista de estos datos, que la declaración como parque natural del Cañón del Río Lobos haya afectado negativamente a la evolución de la cabaña ovina y caprina, que es la más estrechamente relacionada con el territorio. El número de explotaciones también ha descendido, pero a menor ritmo que en estos dos municipios ${ }^{2}$.

Figura 2: Evolución demográfica del parque natural del Cañón del río Lobos $y$ de los municipios rurales de la provincia de Soria, según el Índice 1986=100

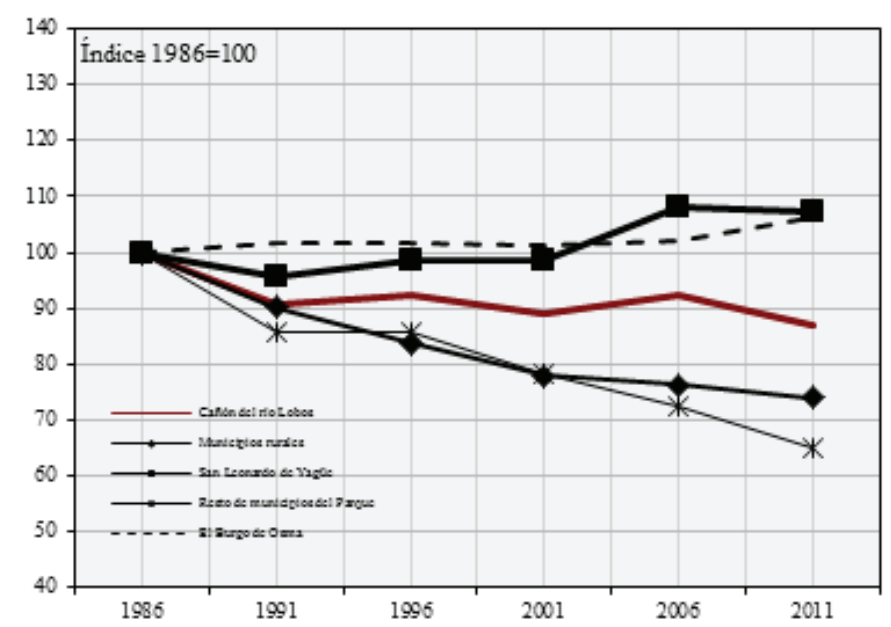

FUENTE: INE, elaboración propia

${ }^{1}$ Datos elaborados a partir de los Libros de licencias de 1986 y 2010, de la Cámara de Comercio e Industria de Soria.

2 Datos obtenidos del Servicio Territorial de de Agricultura y Ganadería de Soria 
La influencia de un espacio natural sobre el sector industrial y el de la construcción puede comprobarse a través de una línea de productos que puedan ser objeto de consumo, tales como artesanía, objetos de regalo, recuerdos o fabricación de pequeños bienes de consumo, que el turista pueda llevarse directamente. El turismo también constituye un gran escaparate para dar a conocer otros productos industriales. La presencia de espacios protegidos en una comarca, a los que se les presume una calidad ambiental, puede resultar también un factor que dinamice el sector de la construcción residencial. En estos sectores, el Cañón del Rio Lobos puede constituir un ejemplo de la contradicción existente entre demanda turística y demanda de inversión. Tanto es así, que el número de licencias industriales se ha reducido a más de la mitad entre 1986 y 2010, cuando en el resto de municipios rurales de la provincia ha aumentado, aunque solo sea un $4,6 \%{ }^{3}$. El sector de la construcción, por su parte, ha permanecido prácticamente estable a lo largo de estos 25 años. Las 40 licencias de 1986 han pasado a 39 en 2010. En el resto de municipios rurales el número de licencias se han elevado de 415 a 519 , lo que supone un incremento del $25 \%$. El hecho de que todos los núcleos de población se sitúen fuera del Parque no ha favorecido el dinamismo del sector, como ha ocurrido en otros espacios protegidos. Por poner un ejemplo, el número total de viviendas entre 1991 y 2001 solo creció en 314, de las cuales tres de cada cuatro se construyeron en San Leonardo de Yagüe 4 .

Cuadro 4: Evolución de la capacidad de acogida y plazas de restauración entre 1986 y 2011

\begin{tabular}{|c|c|c|c|c|c|c|}
\hline & \multicolumn{3}{|c|}{ Cañón del Río Lobos } & \multicolumn{3}{|c|}{$\begin{array}{c}\text { Resto municipios rurales } \\
\text { de Soria }\end{array}$} \\
\hline & 1986 & 2011 & $\begin{array}{c}\% \\
\text { Incrto. }\end{array}$ & 1986 & 2011 & $\begin{array}{c}\% \\
\text { Incrto. }\end{array}$ \\
\hline \multirow{2}{*}{ Alojamiento hoteleros } & 5 & 7 & 40,0 & 21 & 78 & 271,4 \\
\hline & 170 & 363 & 113,5 & 672 & 1.965 & 192,4 \\
\hline \multirow[t]{2}{*}{ Alojamientos rurales } & 0 & 26 & & 0 & 266 & \\
\hline & 0 & 223 & & 0 & 2.534 & \\
\hline \multirow[t]{2}{*}{ Apartamentos } & 0 & 6 & & 0 & 0 & \\
\hline & 0 & 20 & & 0 & 0 & \\
\hline Total plazas / 1.000 habitantes & 41,6 & 170,6 & & 18,4 & 170,19 & \\
\hline \multirow[t]{3}{*}{$\begin{array}{ll}\text { Restaurantes } & \mathrm{N}^{\mathrm{o}}\end{array}$} & 3 & 16 & 433,3 & 69 & 110 & 59,4 \\
\hline & 421 & 1.519 & 260,8 & 2.788 & 8.345 & 199,3 \\
\hline & 103,1 & 427,7 & & 76,39 & 315,6 & \\
\hline
\end{tabular}

FUENTE: Junta de Castilla y León. Elaboración propia.

3 Datos elaborados a partir de los libros de licencias comerciales e industriales de la Cámara Oficial de Comercio e Industria de Soria.

4 Información obtenida de los Censos de Población y Viviendas de 1991 y 2001. 
Uno de los aspectos en los que la gestión del Parque ha hecho más hincapié, a parte de la conservación, es en la función recreativa y turística de los espacios protegidos. Este objetivo ha sido uno de los más exitosos. Pero, ¿Cómo se refleja esto en el desarrollo de infraestructuras y equipamientos turísticos? ¿Ha supuesto la declaración del Parque una ventaja comparativa en relación con otros espacios que no disponen de estos recursos? ¿Se ha aprovechado todo el potencial de desarrollo en los municipios incluidos en las zonas de influencia socioeconómica? La evolución de la capacidad de acogida y de las plazas de restauración desde la fecha de declaración del Parque puede proporcionar una primera cuantificación de los resultados.

La media de plazas hoteleras que registran los municipios del Parque es prácticamente igual al del resto de los municipios rurales de la provincia, por lo que no parece haber ninguna influencia del espacio protegido en el fomento del alojamiento. Aún así, el número de plazas se ha incrementado en mayor medida desde la declaración del Parque que en el resto de núcleos rurales. Respecto al tipo de alojamiento, llama la atención el predominio de las plazas hoteleras sobre los alojamientos rurales, que no se corresponde con la evolución experimentada en el resto de municipios rurales de la provincia. Asimismo, aparecen los apartamentos como forma de alojamiento, que no está representado en los demás. Esta diferente tipología se explica por el sesgo que introduce el municipio de San Leonardo de Yagüe, donde ha prevalecido un tipo de alojamiento hotelero, además con cierto tamaño, sobre todo entre 2001 y 2006. En él se concentra el 89\% de las plazas hoteleras del Cañón.

Una de las bondades que ha introducido la actual normativa sobre alojamientos rurales es la extensión de los establecimientos a una mayoría de municipios. En 1986 solo San Leonardo de Yagüe tenía oferta de alojamiento, mientras que en 2011 hay plazas ya en 6 de los 7 municipios del Parque.

La falta de dinamismo del sector hotelero revela que una buena parte de los turistas realiza una visita rápida y eligen otros centros externos para fijar la estancia. Pero también puede desvelar una falta de información de la oferta existente y una falta de nuevas inversiones para retener una parte más importante del presupuesto de viaje del turista. La falta de población joven emprendedora es un déficit estructural en este espacio. De hecho, hemos podido comprobar que algunos de los alojamientos rurales han sido abiertos por personas que viven fuera de los municipios del Parque, algunos en el Burgo de Osma y otros en Madrid.

Donde más se ha notado la influencia del Parque es en la oferta de restauración, en función del tiempo que debe emplearse para recorrer los distintos sectores del espacio protegido. En este indicador sí que se observa un crecimiento muy 
superior al del resto de municipios rurales de la provincia, y una media de plazas sensiblemente más elevado. Aún con todo, sigue habiendo una desproporción entre las plazas de restauración y el número de turistas, por lo que existe todavía un cierto margen de desarrollo.

Cuadro 5: Evolución del número de licencias comerciales

\begin{tabular}{|l|r|r|r|r|r|}
\hline & & & & \multicolumn{2}{|c|}{ Lic./1000 hab. } \\
\cline { 5 - 6 } & 1986 & 2010 & \% Incrto. & 1986 & \multicolumn{1}{c|}{2010} \\
\hline Municipios del cañón & 86 & 96 & 11,62 & 21,06 & 26,63 \\
\hline Municipios < 2000 habitantes & 836 & 919 & 9,92 & 20,39 & 30,21 \\
\hline
\end{tabular}

FuENTE: Cámara de Comercio e Industria de Soria. Libros de licencias de 1986 y 2010. Elaboración propia.

Tampoco el comercio se ha beneficiado comparativamente de la influencia que haya podido ejercer el Parque, a juzgar por el número medio de licencias. El censo total de licencias comerciales ha crecido algo más que en el resto de municipios rurales, pero su relación actual con la población censada resulta sensiblemente más baja, lo que revela en principio una menor capacidad de atracción. Una situación que puede reproducir la falta de capacidad económica de este espacio para conformar una oferta más diversificada y orientada a la demanda turística.

Aparte de los indicadores demográficos y económicos, habría que considerar otro tipo de indicadores que sirvan para medir el grado de bienestar social de la población, como es el caso de la dotación de infraestructuras y equipamientos colectivos, que constituye un componente cada vez más importante de la calidad de vida de los habitantes. Es en este capítulo donde probablemente las ventajas comparativas sean más visibles. La concepción del Parque como una unidad de cuenca, en la que era preciso actuar en todos los ríos que transcurren o desembocan en el cañón, elemento esencial de la política de conservación, ha determinado que todos los municipios tengan un sistema de saneamiento de aguas residuales prácticamente gratuito, con un técnico que se ocupa del funcionamiento integral de toda la cuenca. Las inversiones realizadas, destinadas a la potabilización del agua, la pavimentación de calles, la mejora del alumbrado, la dotación de algunas infraestructuras deportivas o la rehabilitación de algunos edificios de uso comunitario, engrosan una larga lista que explican la existencia de un nivel de dotaciones comparativamente mejor en los municipios incluidos en el Parque. 


\section{VALORACION DE LOS RESULTADOS}

Cuando se desciende a escala municipal, sobre todo tratándose de poblaciones pequeñas, para valorar el impacto que ha ejercido la protección de un espacio natural y la opinión que se ha forjado entre los vecinos, uno se encuentra con una amalgama de factores que interactúan en distintas direcciones. Hay uno muy importante, que tiene que ver con el tamaño de los pueblos y su capacidad para recuperar una cierta vitalidad económica y demográfica. En este caso, salvo San Leonardo de Yagüe, que tiene un dinamismo vinculado más a la industria que a la presencia del Parque, el resto tiene escasas posibilidades de recuperación, aunque sí de mejora en algunos aspectos. Hay factores de carácter local, ya preexistentes, o derivados de las propias inercias y de las controversias internas provocadas por la declaración. Otros, los más relevantes, tienen que ver con las repercusiones socioeconómicas del nuevo parque creado, el tipo de gestión que se haga del mismo y el sistema de ayudas concedido, así como su reparto entre los distintos municipios.

\section{VI.1 La importancia del movimiento turístico}

La idea de que el turismo y el comercio son los sectores económicos más beneficiados por la declaración de parque natural, es un hecho transversal a toda la pequeña sociedad que compone el territorio del Parque. Sin la existencia, hasta ahora, de un control efectivo de acceso, el Cañón del Río Lobos destaca por la magnitud de la demanda existente, lo que le convierte en un recurso primordial y un factor ineludible de las potencialidades de desarrollo de los municipios incluidos en su área de influencia socioeconómica. Esta aseveración general no está exenta, sin embargo, de cierta controversia por las desigualdades que pueden surgir como consecuencia de la propia configuración física del espacio y las derivadas del tipo de gestión, que son un componente nada despreciable del grado de aprovechamiento de este importante recurso turístico y del nivel de satisfacción de las poblaciones implicadas.

Aunque la declaración del Parque en 1985 significó un repunte de la demanda, no fue, sin embargo, hasta mediados de los 90 cuando se produce la verdadera explosión del número de visitantes, coincidiendo con el desarrollo del turismo rural en España (Fig. 3). El significado de esta demanda queda mejor sopesado si establecemos una comparación con otros espacios naturales de la región, que da como resultado un liderazgo regional en tres de los últimos diez años. 
Figura 3: Evolución de visitantes a las casas del parque del Cañón del río Lobos. 1987-2011

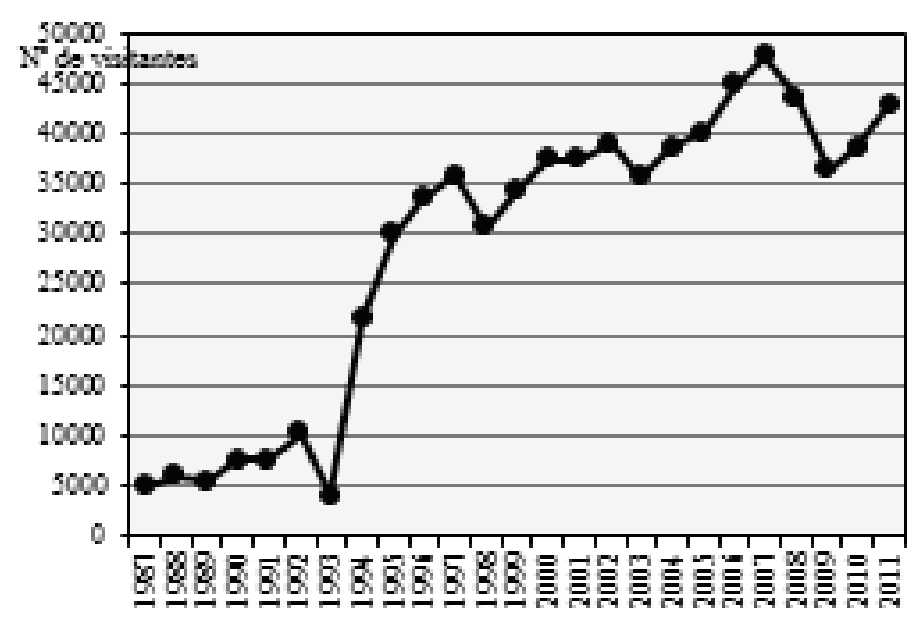

FuENTE: Servicio Territorial de Medio Ambiente de Soria. Elaboración propia

Pero el verdadero impacto, el que mejor percibe la población local, es el registro que se elabora en los lugares de entrada al Parque que, no solo se ajusta más con la realidad, sino que permite establecer comparaciones internas de gran relevancia. Existen tres puntos de información, localizados en las tres puertas de entrada por carretera: Cueva Fría, en la de Ucero, Siete Ojos, en la de San Leonardo de Yagüe, y Hontoria del Pinar. Los datos recabados a lo largo de 88 días ofrecen una primera información del desequilibrio existente entre los tres accesos, lo cual redunda en la percepción de los vecinos (Fig. $\left.n^{\circ} 4\right)$.

De las tres entradas, la primera es la que mayor afluencia registra, debido a su situación estratégica y su proximidad a los enclaves más espectaculares y emblemáticos. Es la puerta de entrada del turismo procedente del sur, principalmente de origen madrileño, que entra a través de la localidad de El Burgo de Osma, cabecera de la comarca y uno de los principales centros turísticos de la provincia de Soria. En esta entrada se sitúa una de las dos casas del parque existentes, la otra se encuentra en San Leonardo de Yagüe. Hasta tal punto es dominante este acceso, que muchos vecinos llegan a identificar el cañón con Ucero, no siendo de extrañar que un $44 \%$ de los entrevistados señalen a éste como el municipio más beneficiado por la declaración del Parque Natural. 
Figura 4: Evolución del $n^{\circ}$ de visitantes a los puntos de información del parque del Cañón del río Lobos. 2003-2010

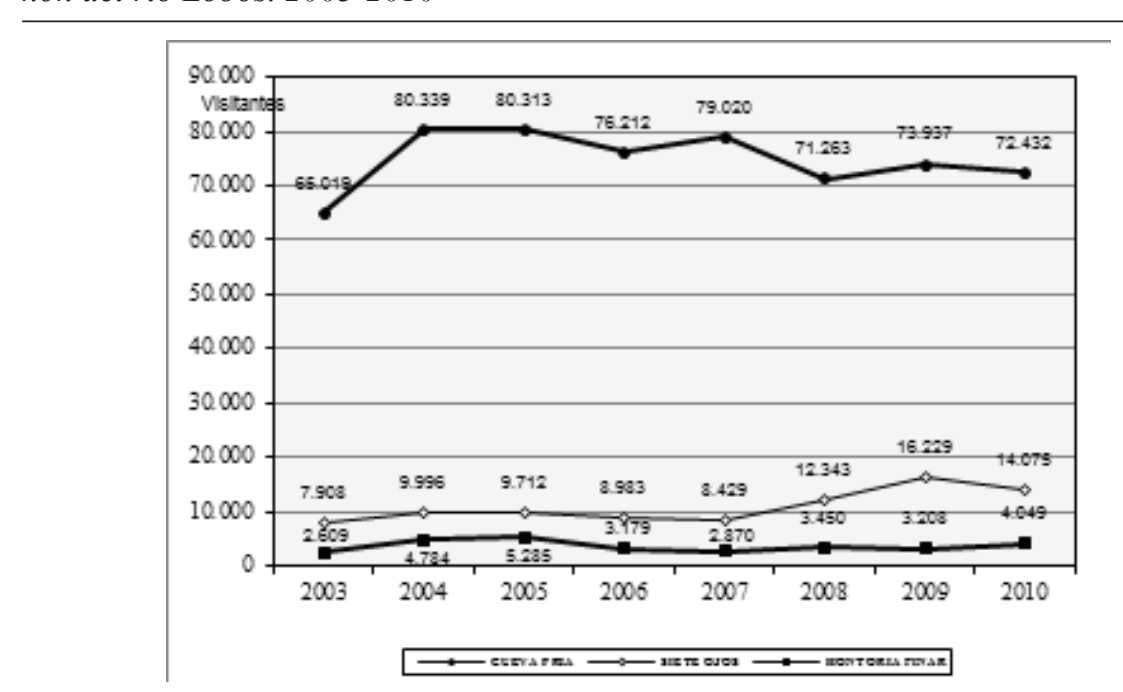

FuENTE: Servicio Territorial de Medio Ambiente de Soria. Elaboración propia

Este desequilibrio se explica porque la mitad de los visitantes que entraron en las casas del parque a lo largo de 2010 procedían de las provincias de Madrid, Barcelona, Zaragoza, Navarra, Valencia y Valladolid, que tienen en este sector su entrada natural (Servicio Territorial de Medio Ambiente, 2011, 63). La relación es menos desigual cuando los visitantes provienen de Vizcaya y Burgos, que tienen su puerta de entrada en el sector septentrional del Parque, y se dividen más equitativamente cuando el origen es la propia provincia de Soria. Pero el hecho de albergar los parajes más atractivos, junto a la facilidad de acceso, explican que la entrada por Ucero sea la preferida por los turistas.

Se trata, por tanto, de una afluencia considerable, pero con marcadas diferencias entre los distintos sectores del Parque, que dan lugar a oportunidades diferentes y no pocas controversias, puesto que el lugar de entrada más frecuentado, Ucero, coincide, a la vez, con el segundo municipio que menos superficie aporta.

\section{VI.2 El papel de la gestión y la política de ayudas de la Junta de Castilla y León}

Otro de los elementos que contribuye a crear posibilidades de desarrollo y a formar una opinión en las poblaciones implicadas es la gestión del Parque 
y, particularmente, la política de ayudas destinadas a los municipios integrados en las Áreas de Influencia Socioeconómica que, en el caso de Castilla y León, vienen reguladas por la ley 8/1991 de 10 de mayo de Espacios Naturales.

La legitimación de las ayudas como un mecanismo de compensación económica a las obligaciones legislativas dirigidas hacia un territorio plantea no pocos debates sobre la finalidad y la orientación estratégica que deben primar en las mismas. El sistema de ayudas ha seguido dos líneas principales: las ayudas a particulares y empresas y las que se destinan a los municipios incluidos dentro de las Zonas de Influencia Socioeconómica (ZIS). Las primeras han sido minoritarias en relación a las destinadas a los municipios, ya que, hasta la fecha, se ha mantenido una política más encaminada a primar a estos por las limitaciones que imponía la declaración del espacio protegido, que ha promocionar iniciativas u otro tipo de actividades. El volumen del primer tipo de ayudas ha mantenido una mayor dependencia de la demanda de inversión existente en los municipios. Esta, por desgracia, ha sido escasa y condicionada además por la no presencia de caseríos en el interior del Parque, que en otros espacios tiende a generar un mayor dinamismo en el sector de la construcción o rehabilitación de viviendas. Esta escasa demanda de inversión repercute en la falta de una infraestructura empresarial capaz de dinamizar y aprovechar la demanda turística.

Las ayudas a los municipios no han estado exentas de cierta polémica por la existencia de diversas alternativas de uso. Podían destinarse a proyectos de mejora del propio espacio natural, o bien a la creación o mejora de infraestructuras y equipamientos dentro del caserío. Estas últimas son precisamente las más solicitadas, con una dedicación casi exclusiva a pavimentación de calles, equipamientos deportivos, mejoras de abastecimiento o rehabilitación de algunos edificios públicos. El reparto trataba de evitar discriminaciones, contemplando dos tipos de asignaciones: una fija, que afecta al 90\% de los fondos, cuya distribución se atiene a tres criterios -la población, matizada por la existencia de una municipio dominante, la superficie aportada al Parque y su valor medioambiental-, y otra variable, que afecta al $10 \%$ restante, que se concede en forma de plus al mejor proyecto presentado. Aparte, se firmaron algunos acuerdos con el gobierno regional, entre los que destaca uno medioambiental, de gran interés, por el que la Junta de Castilla y León se comprometía a sufragar todos los gastos de la instalación de depuradoras y el 50\% de los gastos de mantenimiento. Esta política ha posibilitado que el Cañón del Rio Lobos sea el primer parque con un sistema de depuración integral, de forma que contempla a todos los municipios situados dentro de la cuenca. Con él, se lleva a cabo un sistema de mantenimiento compartido, que 
garantiza un adecuado funcionamiento de todo el sistema y una preservación de la calidad ambiental del Parque. Ello explica el elevado grado de satisfacción por estas infraestructuras que revela la encuesta, a excepción del municipio burgalés de Hontoria del Pinar, por los problemas que ha habido por el funcionamiento de la depuradora.

En el año 2003 se aprobó una nueva normativa, que supuso un pequeño cambio de estrategia en la política de concesión de ayudas. Si hasta entonces se concedían anualmente, a partir de entonces se adjudica una cantidad fija bianual, que asciende a $360.000 €$, lo cual marca una cierta tendencia a la equidistribución de las subvenciones, a la vez que permite a los ayuntamientos realizar una mejor planificación y aspirar a proyectos de mayor envergadura. Si observamos el total de ayudas recibidas, en comparación con la proporción de población y superficie aportada (Fig. 5) pueden establecerse tres niveles de municipios: en el primer nivel se situarían aquéllos que destacan por su población o la superficie aportada; en el segundo entrarían municipios medianos, como Ucero y Casarejos, y en el tercer nivel estarían los más pequeños, que se significan por su escasa población. Del análisis de las otras variables, puede inferirse que hay tres municipios que salen claramente beneficiados, Ucero, Nafría de Ucero y Herrera de Soria, en función de la tercera variable, ya que albergan en sus términos los espacios más atractivos (nacedero del río Ucero, cueva de la Galiana, ermita de San Bartolomé, cueva Grande, etc.). El fondo del cañón sirve de límite entre la mayoría de los términos, pero los lugares más atractivos desde el punto de vista paisajístico y de la demanda de visitantes se encuentran en el sector más alejado de la cabecera del río. Quizá el municipio que más escapa a esta norma es el de Casarejos, que, sin tener especiales valores en la escasa superficie que aporta, obtiene, sin embargo, una proporción mayor de las ayudas. En el otro extremo, se sitúan Hontoria del Pinar y San Leonardo de Yagüe. El primero, aunque obtiene la segunda mejor proporción de ayudas, contrasta, sin embargo, con la superficie y la población aportada; un extremo que se ve reflejado en las encuestas, ya que es la población que mayores objeciones presenta a la gestión del Parque. El hecho de ser el único municipio encuadrado fuera de la provincia de Soria, desde donde se lleva la gestión, es señalada por algunos entrevistados como un factor de discriminación, argumentando precisamente la mayor proporción de superficie aportada al espacio natural. En el segundo caso, se advierte una cierta compensación entre la población y la superficie del término incluida dentro del Parque, como ocurre también en el municipio de Santa María de las Hoyas. 
Figura 5: Participación municipal en las ayudas, la población y la superficie del parque

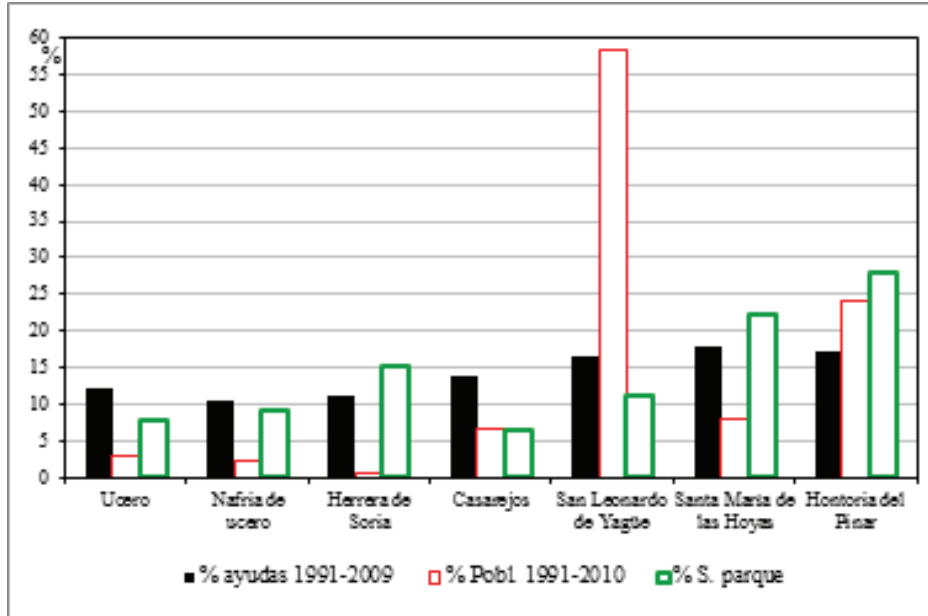

FuENTE: INE y Servicio Territorial de Medio Ambiente de Soria. Elaboración propia

Figura 6: Ayuda media anual per cápita y por ha de superficie aportada en los municipios del Cañón (en euros)

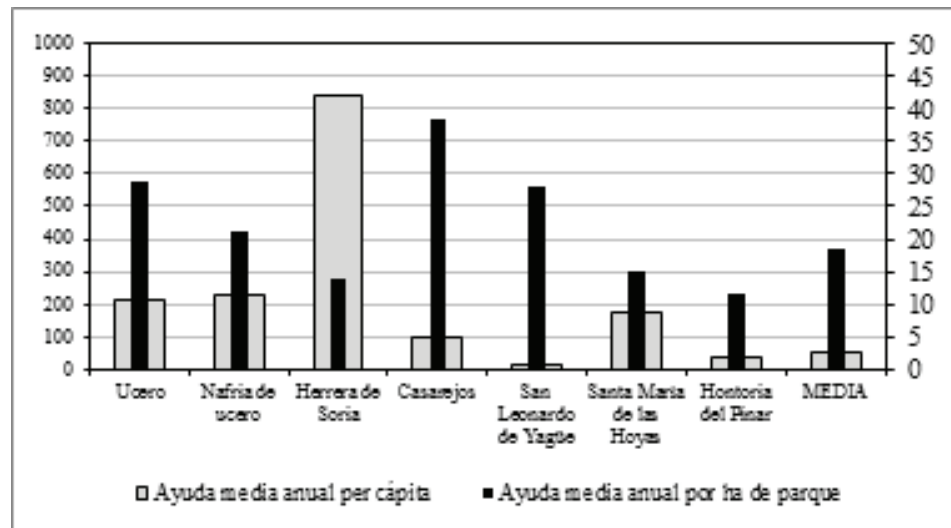

FUENTE: INE y Servicio Territorial de Medio Ambiente de Soria. Elaboración propia

Más significativo resulta, si cabe, la distribución per cápita y por hectárea de las ayudas recibidas (Fig. 6). El gráfico refleja las ventajas comparativas que adquieren los núcleos con menor población, Ucero, Nafría de Ucero y Herrera de Soria. La ayuda media per cápita es claramente superior al resto, si bien en la 
aportación media por ha de Parque hay dos municipios que obtienen mejor resultado, Casarejos y San Leonardo de Yagüe. El gráfico revela también la situación comparativamente peor del municipio de Hontoria del Pinar respecto a este tipo de ayudas, ya que es el único caso en el que las dos variables contempladas se sitúan por debajo de la media.

Figura 7: Evolución anual de la ayudas en euros corrientes y euros constantes

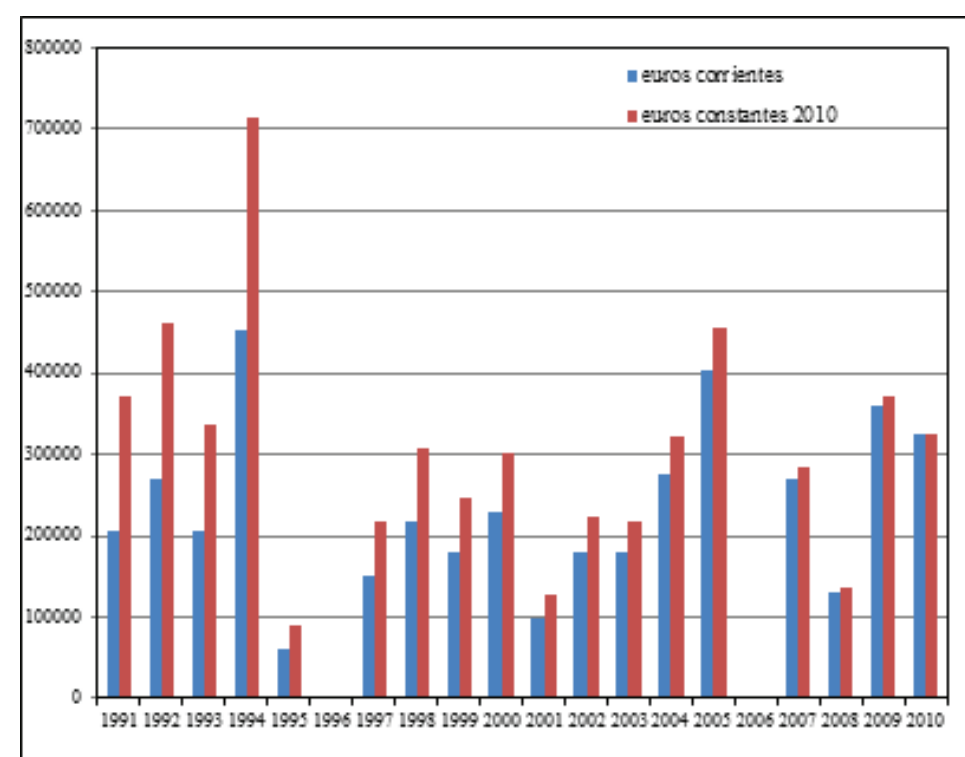

FuENTE: Servicio Territorial de Medio Ambiente de Soria. Elaboración propia

Las ayudas ZIS han pasado por distintas etapas en función de los cambios implementados en el modelo y de las coyunturas económicas. En líneas generales, se puede afirmar que su valor total ha ido perdiendo peso si las cuantificamos en euros constantes de 2010 (Fig. 7). En una primera etapa, entre 1991 y 1994, se fueron concediendo ayudas diferentes cada año, cuya cuantía fue creciendo hasta la llegada de la primera crisis, en 1993. La falta de fondos motivó la desaparición temporal de las ayudas, que queda reflejada en el parón de 1996, ya que las ayudas se van pagando con cierto retraso. Después se reanudaron, con un cierto crecimiento hasta 2005, en que, como consecuencia del cambio de modelo, hubo un año en que no se concedió ninguna ayuda. Con ese cambio se ha ganado en estabilidad, pero se ha ido perdiendo valor.

Para valorar mejor el significado de las ayudas es preciso realizar un análisis específico de cuál es su importancia dentro de los presupuestos municipales. 
Por ello, se ha efectuado un estudio minucioso en el que se incluyen tres variables: la evolución del presupuesto municipal desde el año posterior a la declaración y 25 años después, es decir, en el año 2010, calculado en euros corrientes; la proporción que representa dentro del importe total y en relación con otro tipo de ayudas, y, finalmente, una comparación con otros municipios del entorno, al objeto de que puedan proporcionar elementos de juicio más fundamentados sobre el significado real de estas ayudas para los municipios de la ZIS. Estos municipios son: Valdemaluque, situado al sur del Parque, con 250 habitantes censados en el padrón municipal de 2010, Talveila y Muriel Viejo, al este, con 146 y 75 habitantes respectivamente. A los presupuestos de 2010 se han restado las ayudas derivadas del Plan E, por considerarlas unas subvenciones del estado excepcionales, que podrían distorsionar los resultados.

Si comparamos la tasa media de crecimiento de los presupuestos municipales, se pone de manifiesto que la mayoría de los municipios, sobre todo los más pequeños, consiguen incrementos en sus presupuestos muy por encima de los que alcanzan los municipios vecinos, que no se benefician de las ayudas del Parque. Como se sabe, el alcance de los presupuestos municipales depende sobre todo de los recursos propios y de las ayudas externas. Estas ayudas tienen condiciones distintas según el organismo que las expide. Mientras las ayudas ZIS son subvencionadas al $100 \%$, las que conceden las diputaciones son ayudas solicitadas por los ayuntamientos, que deben participar con un porcentaje, que puede oscilar entre el 20 y el $40 \%$ del presupuesto.

Cuadro 6: Presupuestos municipales y significado de algunas ayudas recibidas

\begin{tabular}{|l|r|r|r|r|r|r|r|r|}
\hline & \multirow{2}{*}{ P. 1986 } & P. 2010 & \multirow{2}{*}{$\begin{array}{c}\text { Tasa } \\
\text { In- } \\
\text { crto. }\end{array}$} & $\begin{array}{c}\text { P. p. } \\
\text { cápita } \\
\mathbf{2 0 1 0}\end{array}$ & \multicolumn{2}{c|}{$\begin{array}{c}\text { Ayudas ZIS } \\
\mathbf{2 0 1 0}\end{array}$} & \multicolumn{2}{c|}{$\begin{array}{c}\text { Ayudas } \\
\text { Diputación } \\
\mathbf{2 0 1 0}\end{array}$} \\
\cline { 5 - 10 } & & & & & TOTAL & \%o & TOTAL & \% \\
\hline Casarejos & $45.394,40$ & 293.732 & 21,9 & $1.392,1$ & 21.000 & 7,1 & 43.602 & 14,8 \\
\hline $\begin{array}{l}\text { Herrera } \\
\text { de Soria }\end{array}$ & $3.606,07$ & 31.450 & 30,9 & $2.246,4$ & 18.648 & 59,2 & 0 & 0 \\
\hline $\begin{array}{l}\text { Nafría de } \\
\text { Ucero }\end{array}$ & $5.306,28$ & 93.689 & 66,6 & $1.767,7$ & 16.742 & 17,8 & 7.685 & 8,2 \\
\hline $\begin{array}{l}\text { San Leo- } \\
\text { nardo de } \\
\text { Yagüe }\end{array}$ & $371.395,42$ & 2.222 .206 & 19,9 & 969,1 & 19.479 & 0,8 & 39.000 & 1,7 \\
\hline $\begin{array}{l}\text { Santa } \\
\text { María de } \\
\text { las Hoyas }\end{array}$ & $24.829,40$ & $232.268,21$ & 33,4 & $1.488,9$ & 23.096 & 9,9 & 40.000 & 17,2 \\
\hline Ucero & $5.095,80$ & $156.204,6$ & 118,6 & 1.562 & 25.064 & 16.0 & 15.900 & 10,1 \\
\hline
\end{tabular}




\begin{tabular}{|c|c|c|c|c|c|c|c|c|}
\hline & \multirow[t]{2}{*}{ P. 1986} & \multirow[t]{2}{*}{ P. 2010} & \multirow[t]{2}{*}{$\begin{array}{c}\text { Tasa } \\
\text { In- } \\
\text { crto. }\end{array}$} & \multirow[t]{2}{*}{$\begin{array}{l}\text { P. p. } \\
\text { cápita } \\
2010\end{array}$} & \multicolumn{2}{|c|}{$\begin{array}{c}\text { Ayudas ZIS } \\
2010\end{array}$} & \multicolumn{2}{|c|}{$\begin{array}{c}\text { Ayudas } \\
\text { Diputación } \\
2010 \\
\end{array}$} \\
\hline & & & & & TOTAL & $\%$ & TOTAL & $\%$ \\
\hline $\begin{array}{l}\text { Hontoria } \\
\text { del Pinar }\end{array}$ & $212.715,63$ & 677.768 .35 & 8,7 & 872,3 & 19.341 & 2,8 & 45.000 & 6,6 \\
\hline $\begin{array}{l}\text { TOTAL } \\
\text { PARQUE }\end{array}$ & 668.343 & $3.707 .318,2$ & 18,2 & $1.028,6$ & 143.370 & 3,8 & 191.187 & 5,1 \\
\hline $\begin{array}{l}\text { Otros mu- } \\
\text { nicipios } \\
\text { vecinos: } \\
\text { Valdema- } \\
\text { luque }\end{array}$ & 38.644 & 222.250 & 19,0 & 889 & 0 & & 54.000 & 24,2 \\
\hline $\begin{array}{l}\text { Talveila } \\
\text { Muriel }\end{array}$ & $48.080,96$ & 269.616 & 18,4 & $1.848,7$ & 0 & & 20.000 & 7,4 \\
\hline Viejo & $16.828,30$ & 93.532 & 18,2 & 1.247 & 0 & & 0 & 0 \\
\hline
\end{tabular}

FuENTE: Secretaría de los ayuntamientos. Elaboración propia

La importancia de las ayudas ZIS puede comprobarse también por el significado que alcanzan dentro de los presupuestos de los municipios más modestos, que llegan a representar un 59\% en el municipio de Herrera de Soria, un 17,8\% en Nafría de Ucero, un 16\% en Ucero o un 9,9\% en Santa María de las Hoyas. Son porcentajes importantes que llegan cada año sin que el municipio tenga que asignar ninguna participación. Las ayudas recibidas por la Diputación, en cambio, pueden tener variaciones anuales importantes, en función de las solicitudes o de las disponibilidades presupuestarias. Todo ello demuestra el importante significado que tienen estas ayudas, dentro de los presupuestos de los municipios integrados en el Parque, tanto más visible cuanta más pequeña es la población.

\section{CONCLUSIONES}

A lo largo de estas páginas se ha intentado profundizar en la influencia socioeconómica de uno de los espacios protegidos más emblemáticos de Castilla y León, el parque natural del Cañón del Río Lobos, al que se ha aplicado un modelo metodológico basado no solo en la mera comparación estadística de una serie de indicadores, sino en la realización de un amplio trabajo de campo para desvelar la opinión de sus propios habitantes. Un parque natural es un espacio vivido por sus vecinos, que han desplegado en él sus usos y costumbres durante generaciones. 
La declaración supone un reconocimiento jurídico a unos valores ambientales, pero también un cambio para la gente que habita y utiliza esos lugares, que con el paso del tiempo puede percibir la influencia que ha podido ejercer en distintos aspectos. Una perfecta sintonía de los vecinos con el Parque es un primer paso para asegurar su conservación y lograr un mejor aprovechamiento de todas sus potencialidades.

La red de espacios naturales protegidos constituye un recurso que ha contribuido de manera notable a lograr el liderazgo que Castilla y León mantiene en turismo rural, con el valor añadido de ayudar al desarrollo de zonas rurales, con mayores problemas estructurales. Han conseguido crear empleo en los sectores más directa o indirectamente relacionados con el turismo, como la hostelería, la restauración y el comercio. Sin embargo, como se ha demostrado en este trabajo, los municipios incluidos dentro de la zona de influencia socioeconómica no siempre han sido los más beneficiados por la presencia de estos recursos. En la práctica, intervienen una diversidad de factores, no siempre controlados desde esos municipios, como la política desarrollada en cada espacio protegido, la ordenación turística en las distintas escalas administrativas, la demanda de inversión en dichos municipios, el interés de las instituciones locales, o la mera presencia de núcleos más dinámicos y emprendedores en los alrededores de los parques.

El Cañón del Río Lobos no solo es el segundo más antiguo de la Región, sino que está en la vanguardia de muchos de los aspectos relacionados con la conservación y el uso público de los espacios naturales protegidos. Sobresale por sus valores geomorfológicos, sus contrastes de luz y color, por la textura de sus relieves, de formas suaves y cortados profundos, y por la rica y variada fauna que anida en sus poderosos farallones. La espectacularidad del relieve, sus paisajes escarpados, sus paseos frescos y plácidos junto al río han sido el reclamo de un número creciente de visitantes, que le han convertido en uno de los parques más frecuentados de Castilla y León. Esa corriente turística no ha producido, sin embargo, un aumento en paralelo de los servicios. Estos han repuntado con cierto retraso y con evidentes desequilibrios internos, en función de la accesibilidad, de la presencia o no de una población joven emprendedora y también de la gestión, de la que deben ser conscientes los responsables públicos.

La opinión de la población no deja lugar a dudas de que el Parque ha favorecido el desarrollo de los municipios que lo integran. A juicio de los vecinos, la hostelería y el comercio son los sectores más beneficiados, y las actividades agrarias las más perjudicadas, aunque de hecho no se aprecia que el impacto sea muy negativo. Existe un consenso muy amplio sobre cuál es el municipio más favorecido, que señala en primer lugar a Ucero y en segundo a San Leonardo de 
Yagüe, aunque hay un núcleo externo, El Burgo de Osma, al que un 24\% apunta como el más beneficiado en función de su tamaño, localización y otras ventajas derivadas de la política de infraestructuras.

También se deriva de las encuestas un cierto orgullo de pertenencia al espacio protegido, más visible en la población adulta-joven que en la población adulta. Este reconocimiento del Parque como algo propio justifica el debate existente entre conservación y uso público, o si el destino de las ayudas debe dirigirse a crear equipamientos en los pueblos, a mejorar el espacio natural o a estimular el desarrollo, con una clara división entre los encuestados. El hecho de que las limitaciones impuestas han afectado más al uso social que al manejo del medio, ha favorecido que con el tiempo se hayan aceptado como razonables y coherentes con los objetivos de conservación.

El análisis de los indicadores corroboran solo en parte las opiniones dadas por los distintos colectivos. Aunque la evaluación por los métodos puramente cuantitativos tiene una difícil aplicación, los distintos indicadores manejados no permiten hablar claramente de una influencia socioeconómica del Parque sobre los municipios incluidos dentro de él. Los indicadores demográficos reflejan una evolución y unos valores mejores que los de la media de los municipios rurales de la provincia de Soria; pero si restamos el peso de la población industrial de San Leonardo, estos son francamente peores. Ahora bien, si comparamos la evolución del conjunto de municipios del Parque con la trayectoria que han seguido otras comarcas de la provincia, se puede afirmar que el comportamiento ha sido mucho mejor.

A la misma conclusión se llega si analizamos la evolución del número total de licencias entre 1986 y 2010, que arroja un incremento muy inferior al mantenido en el resto de municipios rurales. Un análisis por sectores desvela algunas diferencias. Así, la actividad industrial y la construcción apenas se han visto dinamizadas por la declaración del Parque, ni la capacidad de acogida ha experimentado una evolución más acelerada que la del resto de los municipios rurales de Soria. Lo mismo le ocurre al comercio, cuyo número de licencias ha evolucionado casi en paralelo con la media provincial, aunque su tasa media de licencias resulta sensiblemente inferior. El único sector que se ve más claramente favorecido es el de la restauración, con un incremento de plazas notablemente superior al que experimentan el conjunto de la Soria rural, con una media de plazas por cada 1.000 habitantes situado muy por encima de esa referencia. En contra de lo que podría pensarse de antemano, la protección de este espacio no ha tenido un impacto negativo sobre el sector agrario, si se lo compara con otros municipios 
de su entorno. Tanto el número de explotaciones como la cabaña ganadera han evolucionado incluso mejor que en otros municipios colindantes

La mejora también se percibe en el nivel de infraestructuras y equipamientos colectivos, consecuencia directa de la política de ayudas, destinadas a compensar las limitaciones legislativas impuestas por la declaración. Estas ayudas representan un porcentaje importante del presupuesto municipal, sobre todo en los núcleos más pequeños, y se han destinado a mejorar sus infraestructuras y equipamientos colectivos, más que a la conservación del Parque o al estímulo de actividades económicas. Este es uno de los aspectos más visibles de la positiva influencia que el Parque ha ejercido sobre los municipios incluidos dentro de él y también uno de los mejor valorados por los vecinos.

De todo ello se deduce que es difícil hablar, de una forma genérica, de la influencia socioeconómica de este espacio natural protegido. Esta conclusión parece contradecir las opiniones expresadas por la población local, si bien una buena parte de los encuestados admitía que los beneficios eran poco destacados o que hay municipios externos que han resultado más claramente favorecidos. Los datos evidencian precisamente una clara desconexión entre la iniciativa privada y el Parque, que ha sido reemplazada por otras poblaciones de los alrededores. Todo esto no significa, en absoluto, que algunos espacios naturales puedan cuestionar la condición de motores del desarrollo socioeconómico en las áreas rurales de la comunidad; lo único que explica es que los parques son capaces de irradiar el desarrollo más allá de sus zonas de influencia socioeconómica. Ello no impide tampoco que los municipios incluidos dentro de ellos no se beneficien de unas inversiones que han mejorado considerablemente sus niveles dotacionales.

La exposición de estos resultados no presupone necesariamente tener que abogar por una necesidad de cambio, aunque la situación en el medio rural soriano sea especialmente delicada. El Cañón del Río Lobos puede constituir un ejemplo de contradicción entre potencialidades de desarrollo y niveles reales de aprovechamiento. Quizá sea cuestión de tiempo que puedan surgir nuevas iniciativas. Pero si realmente se quiere ayudar al desarrollo socioeconómico de estos espacios protegidos, desde la administración regional se podría hacer más para estimular la iniciativa privada, preparando planes de desarrollo más ambiciosos, planteando nuevas opciones recreativas, compatibles con la conservación, o reorientando la concepción de las ayudas ZIS. También se echa en falta una mayor cooperación entre los ayuntamientos implicados para poner en valor nuevos recursos o desarrollar proyectos en común. 


\section{BIBIOGRAFÍA}

Bachiller Martínez, J. (2007): “El parque natural del cañón del río Lobos: un ejemplo de planificación razonable, con unos aceptables resultados socioeconómicos y ambientales". III Coloquio hispano-francés de Geografía Rural. Baeza, AGE-Universidad Internacional de Andalucía. p. 267-282.

Cascos Maraña, C. y Guerra Velasco, J.c. (2000): “Los espacios naturales protegidos en Castilla y León: Un plan ambicioso entre la escasez de medios y un futuro incierto". En Valle Buenestado, B (Coord.). Geografía y espacios protegidos. Murcia, AGE y FENPA.

Hidalgo Morán, S. (2006): Uso público en parques naturales. Análisis comparado de Andalucía y Castilla y León. Granada, Editorial de la Universidad de Granada.

JUNTA DE CASTILLA Y LEON (2003): Libro del parque natural del cañón del río Lobos. Programa de parques naturales de Castilla y León. Valladolid, Consejería de Medio Ambiente.

JUNTA DE CASTILLA Y LEÓN (2009): Plan estratégico del turismo de Castilla y León, 2009-2013. Valladolid, Consejería de Cultura y Turismo.

Martinez Vega, J. y Romero Calcerrada, R. (2003): "Repercusión de los espacios naturales protegidos en la economía rural española". Serie geográfica, no 11 , Madrid, Departamento de Geografía, Universidad de Alcalá, p.41-60.

Mediavilla García, C y otros (2012): La red de parques nacionales en la sociedad. Estudio explicativo sobre la percepción social de la red de parques nacionales. Cuadernos de la red de parques nacionales. $\mathrm{N}^{\mathrm{O}}$ 1. Madrid, Ministerio de Agricultura, Alimentación y Medio Ambiente.

Meneses Canalejo, J. M. (Coord.) (1995): El cañón del río Lobos. Segovia, Junta de Castilla y León.

MorÁn Rodríguez, Ma .A. (2002): "El turismo en los espacios rurales y naturales de Castilla y León, como base del desarrollo rural". Anales de Geografía de la Universidad Complutense. Vol. 22. Madrid.

Mulero Mendigorri, A. y Garzón García, R. (2005): "Espacios naturales protegidos y desarrollo rural en España”. Ería, no 68. Oviedo, Universidad de Oviedo, p. 315-330.

OJEDA Rivera, J. F. (2000): "Espacios naturales protegidos y desarrollo sostenible”. En: VALLE BuENESTADO, B.: Geografía y espacios protegidos. Murcia: Asociación de Geógrafos Españoles/Federación de Espacios Protegidos de Andalucía, p. 273-286.

Rico GonZÁlEz, M. (2005): "El turismo como nueva fuente de ingresos en Castilla y León”. Cuadernos de turismo, ${ }^{\circ}$ 16. Murcia, Universidad de Murcia, p. 175-195.

Ruiz Urrestarazu, E. y Galdos Urrutia, R (2007): "Los espacios protegidos en el País Vasco". En: Espacios naturales protegidos. III coloquio Hispano-francés de Geografia Rural. Baeza, 28 a 30 de mayo de 2007.

Sanz Perez, E., Segovia Rosales, R. y Meneses Canalejo, J. M. (2010): Guía geológica del cañón del río Lobos. Soria, Excma. Diputación Provincial de Soria.

SERVICIO DE MEDIO AMBIENTE DE SORIA (2012): "Memoria de visitantes al cañón del río Lobos 2011”. Soria. 
